\section{Agency in Human-Smart Device Relationships: An Exploratory Study}

Heidi Toivonen

Francesco Lelli

\begin{abstract}
In this paper, we investigate the relationship people have with their smart devices. We use the concept of agency to capture aspects of users' sense of mastery as they relate to their device. This study gives preliminary evidence of the existence of two independent dimensions of agency for modeling the interaction between humans and smart devices: (i) user agency and (ii) device agency. These constructs emerged from an exploratory factorial analysis conducted on a survey data collected from 587 participants. In addition, we investigate the correlation between user agency and device agency with background variables of the respondents. Finally, we argue that mapping the users' dynamics with their device into user agency and device agency fosters a better understanding of the needs of the users and helps in designing interfaces tailored for the specific capabilities and expectations of the users.
\end{abstract}

\section{Keywords}

Agency, smart devices, IoT, Device Agency, User Agency, Human Computer Interaction, HCI, Questionnaire, exploratory analysis, anova

\section{Introduction}

Smart devices with increasingly sophisticated features continue to enter into every corner of our homes and personal lives, invoking questions of how we relate to them. As smart objects have capabilities that exceed those of other, "nonsmart" everyday objects, it is relevant to ask whether we own them or they own us. In this paper, we advocate that a better understanding of the relationships that humans form with their smart devices can improve the design and development of the related user interfaces. We argue that two aspects play an important role in the way we establish relationships with devices:

(i) User agency, that is, the level of perceived mastery and ability to use the device in a meaningful manner and

(ii) Device agency, the combination of independent abilities the user is willing to attribute to the device.

The field of Human-Computer Interaction has for long recognized agency as a key factor in people's interactions with technology, albeit it has usually been defined narrowly as merely the experience of being in control of the device [1], [2]. We argue that an understanding of user's sense of agency and the agency they give to the device can foster a more empowered relationship between user and device. In this respect, we also revisit the seminal work of Gibson and his concept of affordances [3] as further described in Section 2.

In this paper, we use the concept of "user agency" to refer to a multi-level sense of mastery that people have in relation with their smart devices. This definition is not in conflict with the understanding of agency in classical HumanComputer Interaction. At the same time, it borrows from psychology to better capture the variety of users' beliefs of their mastery ad abilities to use devices [4]. In analogy with this definition, the notion of "device agency" refers to a collection of abilities attributed to the device by the user.

In Section 5, we theorize that the relationships that users have with their devices can be categorized into four classes according to the dimensions of user agency and device agency.

We developed an exploratory survey that consists of 35 questions concerning various aspects in how the users relate to a specific smart device of their own choosing and how they view this device and themselves as users. Responses of 587 people representing a variety of nationalities have been analyzed in Section 4. In particular, our exploratory factor analysis shows preliminary evidence that the constructs of user agency and device agency can be used to explain a large 
portion of the dynamics between humans and their smart devices.

The rest of this paper is organized as follows: Section 2 presents the various definitions of agency as described in literature. Section 3 introduces the survey and presents an overview of the collected data. Section 4 reports the findings of our exploratory factorial analysis and shows how user agency and device agency vary according to background variables such as the respondents' age, gender, etc. Section 5 discusses some of the theoretical implications of the study for the designing of interfaces and HumanComputer Interaction in general. Finally, in Section 6, we present our conclusions.

\section{Agency in human-technology interaction}

Scholars of several disciplines, HCI included, touch the notion of agency in a direct or indirect manner, which has resulted in a multiplicity of differing definitions of the concept.

In Human-Computer Interaction, the concept of agency has been used to denote being in control of technology, often measured with relatively simple motor-cognitive tasks [1], [5], [6].

In psychology, agency is often seen to encompass wider phenomena such as motivation, incentive, and ability to initiate actions that have an influence in the outside world [7], [8], [9]. An agentic person can recognize himself as the originator of his own experiences and actions, not attributing them to an outside source [9], [10].

Taking a look into the history of agencyrelated concepts brings us to the theory of affordances. According to Gibson, an affordance is the directly perceivable possibility for action that an environment provides for an actor. The changing need of the observer influences whether the affordance is perceived, but it is always there and not bestowed upon an object by an observer [3]. According to Norman in [11], affordance refers to the perceived and actual designed-in properties of an object, especially such fundamental ones that determine how the object can be used.
Hutchby in [12] adapted the notion of affordances for the sociology of science and technology to converge the opposing poles of constructivism (technology as a tabula rasa that people give meaning to) versus determinism (technology makes people act in a specific way). The notion of affordance challenges the usercentered idea that technology amounts only to what the users make of it; affordances are both enabling and constraining people's actions. Thus, technology has independent qualities that are not only dependent on the user. It has been argued that an affordance exists as a relationship between an actor and an artefact and emerges from both the user's characteristics and the object's features [12], [13]. In this paper, we see users as attributing agentic capabilities to technological devices while acknowledging that these attributed capabilities are not the same as the actual potentials of the device.

In the HCI field, agency often boils down to the user's perception of who/what initiated an action; for example, users tend to perceive simple actions and their effects in a different way depending on where they see the source of the action to lie [1], [5], [6], [10], [14]. In addition, Human motor cognition refers to "intentional binding" as a psychophysiological measure of an implicit component of agency. This aspect refers to how people judge the perceived time between the voluntary initiation of action and its consequent effects [1], [5], [6].

Both the user's sense of agency and their attributions of agency to technology are relevant when exploring humans' relations with technology and developing interfaces [1]. Scholars debate around two opposite poles: Humans as free to exercise their agency over technology versus technology as constraining and restricting [15]. Findings from social psychology, perceptualmotor research, and affective computing indicate that people tend to attribute human-like agency to interactive systems that are sufficiently complex, and these attributions influence the way humans interact with technology [5], [6]. Traditionally, only humans have been viewed as able to initiate intentional actions caused by mental states [16]. 
Such classical definitions of human versus technological agency should be revisited. In particular, it should be taken into account that smart objects are not just passive entities that the user invests with meaning, but have degrees of agency, autonomy, and authority of their own [17].

Previous research has presented a few attempts of modeling human-computer relationships. For example, Novak and Hoffman in [17] display a model of consumer-object relationships, where four main interaction patterns between objects and consumers emerge based on the dimensions of agency and communal orientation. In addition, authors in [19] argued that interactions increase when users feel superior to their device and see it as a servant. At the same time, those viewing the object as a partner or master build non-beneficial relationships that make them reluctant to interact with the objects.

The current main trend in theory and research reflects the balancing of arguments: Technology both enables and constrains human action and becomes enacted from human agency [12], [15], [16], [17]. Recent discussions have emphasized the need to explore people's relationships and experiences with technology more holistically [20], [21], [22]. McCarthy and Wright in [9] have advocated a felt-life approach to people's relationship with technology, approaching agency as a crucial element of subjectivity: People feel agentic when they are able to do things in an authentic way that supports their sense of self.

The shared challenge in the $\mathrm{HCI}$ community is to develop ways to maintain the human's sense of agency in relation to the system [1], [14], [19]. This has also been formulated in the seventh golden rule of interface design: The user should sustain the feeling of control over a system that they feel is responsive to their actions [19].

\section{Empirical evidence of agency in human and smart device relationships}

In this paper, we propose a theory of agency in human-smart device interaction and present empirical evidence supporting these theoretical postulations. With user agency, we refer to a collection of beliefs regarding one's abilities to use a smart device in a meaningful manner. Device agency refers to a variety of beliefs regarding capacities that the device has.

We conceptualize user agency as a dimension that evolves from low agency (a sense of not being able to master one's device optimally) to high agency (a sense of mastery of one's device). Likewise, device agency is seen as a dimension with a low end (the device as not able) and a high end (the device as having capacities of its own). According to our theorizing, user agency and device agency are independent dimensions, suggesting that a person can simultaneously be high in both or low in both. This creates the matrix of possible user-device relationships, as presented in Figure 1. A controller attributes agency to himself but not to the device. In essence, he sees himself as an able user, and the device does not have any capabilities independent of him. A collaborator sees his device helpful and useful and, at the same time, he perceives himself as capable to use it. A victim is a user that scores low in agency but attributes high agency to their device. In other words, the device is able to do things and the user not, to the point where they feel dominated by the device. A detached user is attributing low agency to himself while also attributing low agency to the device. He feels unable with the device, but also sees the device as not useful or helpful.

\subsection{Operationalizing agency}

We developed a new survey with the aim of defining these new concepts of user agency and device agency in the context of human-smart device interaction. This survey intended to be exploratory in nature and to our knowledge, there are no pre-existing, validated scales of user and device agency. Thus, we started by formulating a variety of questions related to user and device agency based on a literature review as mentioned 
in Section 2 further elaborated in Section 3.2. We defined user agency broadly as a collection of beliefs and experiences of cognitive and behavioral abilities in terms of using the smart device. Accordingly, device agency was defined as a set of capabilities attributed to the device. Next, we formulated 16 questions capturing the agency of the user and the device: four questions of high user agency, four on low user agency, four on high device agency and four on low device agency. Thus, the survey was designed to include 8 questions of user agency and 8 of agency attributed to the device.

Below, we present the grouping of all agency-related questions according to whether they represent high user agency, low user agency, high device agency, or low device agency.

\section{High user agency was measured with:}

- Q_1 I'm positive about having this smart device as a part of my daily life;

- Q_5 It is me, the user, who is in control of stopping tasks/processes with my smart device;

- Q_9 I understand how this smart device works;

- Q_13 I am using this smart device to execute task(s) that I have freely chosen.

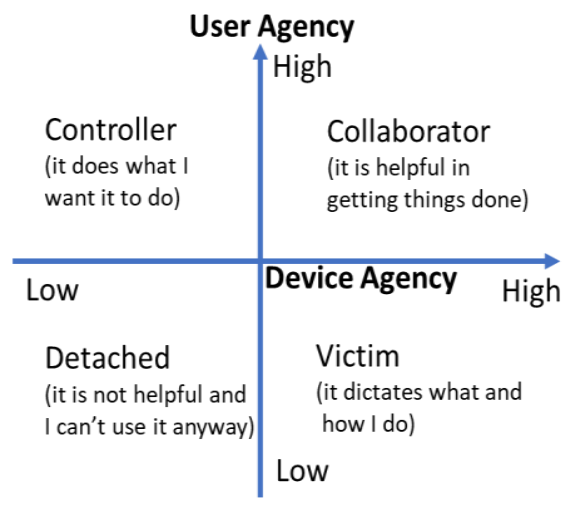

Figure 1. Device and User Agency

Low user agency was measured with:

- Q_2 I often feel victimized by my smart device, like it does things to me rather than the other way around;

- Q_6 I am not able to change the way I do things if my smart device is involved; it forces a certain process on me;
- Q_10 I have often had a less than ideal way of using my smart device in the past;

- Q_14 I often think that I cannot really use my smart device to achieve the things I want.

High device agency was measured with:

- Q_3 The smart device runs its actions independently of me/does what it does on its own;

- Q_8 My smart device has intelligence and understanding of its own, independent of me;

- Q_11 My smart device is a true active participant in the interaction I have with it;

- Q_15 Certain things are performed better by my smart device than by me.

Low device agency was measured with:

- Q_4 I feel that my smart device cannot initiate actions on its own;

- Q_7 This smart device cannot independently change the course in how a task is completed;

- Q_12 My smart device is fundamentally dependent on me, the human user;

- Q_16 My smart device is not really helpful in getting things done.

This exploratory study aimed to develop a preliminary conceptualization of agency in human-smart device interaction and investigate this with a new survey. The statistical analyses conducted with SPSS were exploratory, not confirmatory, in nature, and serve a theorybuilding more than a theory-confirming purpose.

\subsection{An overview of the survey}

The survey started with a section on the dimensions of user agency and device agency, for which altogether 16 items were designed as explained in Section 3.1. We also developed scales for other constructs and elements that $\mathrm{HCI}$ and other scholars have considered relevant in characterizing human interaction with (technological) objects. These scales include:

- usability, the pragmatic attributes, or functionality of the device [20], [21],[22], 
- cost-effectiveness or price utility, the perceived efficient use of money [23],

- self-extension or identification with the device [21], [24],

- the social aspect of devices, such as social status or social self-image expression [21], [22], [23] and their capacity to enhance the user's social relationships [23],

- the emotional aspects of using the device, such as joy or aesthetic pleasure [21], [22], and

- anthropomorphism, attributing human-like qualities to the device [17], [25].

All constructs were measured using multi-item scales designed for the purposes of this study. The survey included also a set of questions for prequalifying and segmenting the population, including items concerning the respondents' gender, age, and educational and professional background.

\subsection{Data collection}

For this first version of the survey, we specifically targeted IT and IM/IS experts, with and without domain specific knowledge. Both academics and practitioners were included in the sample, as well as people involved in the smart device value chain. The survey was also shared on different social media, and people were actively encouraged to share the survey in their own personal and professional channels.

Data was collected with Qualtrics in an anonymous format and are stored at the University of Tilburg in complacence with GDPR. The data will be available for the scientific community for the coming 10 years in order to ensure reproducibility of the results as well as to promote future collaborations.

As a part of the survey, the respondents were asked about their interest in taking part in an interview about their smart device use. We also have started collecting and analyzing feedback about the survey to support its future development.

\section{Data analysis and results}

Data was originally obtained from 809 participants. After removing all respondents that did not answer to all questions, the final dataset included 587 cases. Because the survey was distributed via the authors' personal and professional networks, the sample is constituted of highly educated professionals, many of which can be considered remarkably familiar with technology. This naturally affects the generalizability of our results but on the other hand, provides a unique look into the agency of a very specific group of users. For example, 38.3\% of the respondents are professors. In addition, $53.7 \%$ work in Informatics, Computer Science, or Computer engineering, and $83 \%$ of the respondents say they have professional knowledge of one or more of the following disciplines: (i) Internet of Things, (ii) Human Computer Interaction, (iii) Artificial Intelligence, (iv) Big Data, or (v) Requirement Engineering. Finally, $68.9 \%$ of the respondents were male and $29.9 \%$ female.

In the survey, we asked the respondents to choose one smart device and keep it mind while answering the questions. In case the respondent did not own any other smart device, they were encouraged to choose their computer or mobile phone. "Smart watches and bracelets" ( $24.9 \%$ of the respondents).

\subsection{Exploratory Factorial Analysis}

The main aims of the exploratory factorial analysis were to:

(i) investigate the patterning of the variables specified in Section 3.

(ii) In addition, we studied whether and how the dimensions of user agency and device agency would emerge from the data.

In building the survey, seeking a high intra-construct reliability was not our main priority. The intention behind the survey was to explore a variety of nuances of user and device agency and to investigate their behavior in the exploratory factorial analysis. As expected, the Cronbach alphas for these subscales were not 
high: 0.44 for device agency and 0.62 for user agency.

A Principal Axis Factor analysis with oblique rotation (Promax) was conducted on the 35 questions in the survey. The Kaiser-MeyerOlkin measure $(\mathrm{KMO}=0.84)$ verified the sampling adequacy for the analysis. All except six of the KMO values for individual items were greater than 0.5, and as these items were not related to the emergent agency factors, they were not included in further analyses. Eight factors had eigenvalues over Kaiser's criterion of 1 , and in combination, they explained $54.89 \%$ of the variance. The scree plot was ambiguous with inflexions that would justify retaining 2, 4, 6, or 8 factors. Six of the factors made theoretical and conceptual sense (user agency, device agency, self-extension, functionality, anthropomorphism, feelings). In this study, we will be focusing on two of the factors: User agency and device agency. The items that loaded on these two factors in the initial factor analysis all came from the agency scales described in Section 3.1.

Next, we proceeded to run another exploratory factor analysis on the 16 agency items. We conducted a Principal Axis Factor analysis with oblique rotation (Promax) extracting two factors. The KMO was 0.78 , confirming the sampling adequacy. The factors, device agency and user agency, had eigenvalues of 3.34 and 2.07, respectively, and explained $33.81 \%$ of the variance.

We aimed to obtain a simple factorial structure [26], where each factor has a few high loadings and the rest of them are zero or close to zero. Therefore, we removed variables that had no loadings on either factor, had low loadings, or had cross-loading on both factors, deleting one variable at a time. In this case, $\mathrm{KMO}$ was 0.7 .

Table 1: Exploratory Factorial Analysis

\begin{tabular}{rc}
\hline \multicolumn{1}{l}{ Factor } & Loadings \\
\hline Useragency & \\
Items & \\
Q_14 & 0.737 \\
Q_10 & 0.532 \\
Q_16 & 0.488
\end{tabular}

\begin{tabular}{cl}
\hline Q_6 & 0.420 \\
Eigenvalues & $\mathbf{1 . 8 2}$ \\
\% of Variance & $\mathbf{2 . 7 9}$ \\
Composite Reliability & $\mathbf{0 . 6 6}$ \\
\hline Deviceagency & \\
Items & \\
Q_5 & 0.672 \\
Q_4 & 0.571 \\
Q_12 & 0.562 \\
Q_7 & 0.482 \\
Eigenvalues & $\mathbf{2 . 1 0}$ \\
\% of Variance & $\mathbf{2 6 . 2 8}$ \\
Composite Reliability & $\mathbf{0 . 6 2}$ \\
\hline Interconstruct correlation & -0.14 \\
Cumulative variance explained & \\
by both factors & $49.07 \%$ \\
\hline
\end{tabular}

Table 1 presents the final factor structure: It shows significant loadings on both factors, no cross-loadings, and good internal consistency of the scales. In addition, in selecting the final elements, we considered the fact that in a sample size greater than 100, factor loadings of .30 can be considered significant [26]. The Cronbach's alphas for these new constructs were 0.66 for device agency and 0.62 for user agency. According to authors in [27] Cronbach alpha measures the internal consistency of a scale and values of 0.60.7 are acceptable, especially in an exploratory study with a new scale. In addition, these concepts have almost zero correlation with each other and present eigenvalues of 1.82 and 2.1. Finally, they account for $49 \%$ of the variance in the sample, thus supporting the validity of these two constructs.

The resulting factors also make theoretical sense as the questions in each group clearly refer to user and device agency. Moreover, Table 1 shows how three items from the scale low user agency, describing the user's sense of not being able to use the device in an optimal manner, loaded on the other factor with one item from the scale low device agency (My smart device is not really helpful in getting things done). These items reflect the user's low agency or lack of agency with the device. For reasons of clarity, in forming the final construct, we turned the scales of these 
variables so that higher scores on the final construct would reflect higher user agency.

The other factor consists of three items from the scale low device agency that loaded together with one item from the scale high user agency (It is me, the user, who is in control of stopping tasks/processes with my smart device). In forming the final construct, we used variables with turned scales in order to create the construct of Device agency. In this way, the higher the score on this construct, the more the user attributes agency to the device.

In the factor analysis, the high agency items did not behave as originally expected. For example, two items from the high user agency scale (I understand how this device works and Certain things are performed better by my smart device than by me) did not have any loadings on either factor. This points to the possibility that the user's positive feelings and their understanding of the device are not related to the agency of the user.

In summary, the exploratory factorial analysis shows the solidity of our constructs, in particular that agency as attributed to humans and agency attributed to devices are indeed two separate concepts and reflect two distinct phenomena of agency in human-smart device interaction.

\subsection{On sub-segmenting the sample: Agency and the background variables}

As explained in Section 4.1, the exploratory factorial analysis suggested the soundness of the constructs. Therefore, we investigated the behavior of user agency and device agency in different segments of the population. More specifically, we investigated whether the levels of scores on user agency and device agency would vary according to the following background variables: the respondents' (1) age, (2) gender, (3) educational level, (4) professional field, (5) working experience, (6) working situation, (7) professional knowledge of one or more of the following disciplines: (i) Internet of Things, (ii) Human Computer Interaction, (iii) Artificial
Intelligence, (iv) Big Data, or (v) Requirement Engineering. The survey also included a question concerning (8) whether the respondent had been professionally involved in researching, producing, marketing, or selling smart devices, and (9) the category of device they wanted to focus on when responding to the survey.

There were violations to the normality of data when assessed with the Shapiro-Wilk test, analysis of skewness and kurtosis, and a visual inspection of the histograms. We conducted all the analyses first with non-parametric tests that do not assume normality. Then, for reasons of comparison, analyzes were conducted with their parametric equivalents. In both cases, we obtained exactly the same results. A recent work [27] points to the fact that ANOVA is robust also with non-normal data and is to be preferred over the weaker Kruskall-Wallis. Therefore, in sections 4.3 and 4.4 we will present the results of ANOVA and other parametric tests. The following nonparametric tests were conducted:

- Kruskall-Wallis to investigate the effect on user and device agency of the background variables that have more than 2 groups (i.e. all except (7) professional knowledge and (8) professional experience).

- As post hoc: Dunn's pairwise comparisons to investigate which of the subgroups of the background variables had a significant impact on our constructs.

- Mann-Whitney for investigating whether the levels of user and device agency differed according the binary background variables of professional knowledge and professional experience.

The following parametric tests were conducted:

- one-way ANOVA to investigate the effect on user and device agency of the background variables that have more than 2 groups (i.e. all except (7) professional knowledge and (8) professional experience).

- as post hoc: (i) Tukey, (ii) Bonferroni, (iii) Games-Howell, and (iv) Gabriel to investigate further which were the groups of the background variables that differed significantly from each other in terms of user 
and device agency. All of these tests gave identical results. Because our sample sizes were nonidentical, the results reported in the next sections are obtained with Gabriel.

- Independent samples $t$-test for investigating the effect of binary background variables (professional knowledge and professional experience).

\subsection{Background variables' impact on user agency}

The mean of user agency in our sample was 2.44 , indicating a moderate level on the scale 1-5 where 5 indicate the highest level of agency. In all analyses, Levene's test was used to investigate whether the variances of the different groups based on the segmenting variables of 1-9 (see section 4.2) have significantly different variances [29].

In terms of (1) age, the Levene's F test revealed that the homogeneity of variances assumption was not met $(\mathrm{p}<.05)$. Thus, we used the Welch's adjusted F ratio. A one-way ANOVA showed that age did not have a significant effect on user agency $\left(\right.$ Welch's $\mathrm{F}_{4,223.77}=2.30, \mathrm{p}>.05$, est. $\left.0^{2}=.01\right)$.

There was no significant effect of (2) respondent's sex $\left(F_{2,584}=0.662, \mathrm{~ns}, \mathrm{n}^{2}=.002\right)$ on user agency as determined by one-way ANOVA. Because we only had six respondents who did not identify as male or female, we also ran an independent samples $t$-test with only those who identified as either male or female, and obtained the same result: sex has no effect on user agency $(\mathfrak{t}(579)=0.614, \mathrm{p}<.05, \mathrm{r}=.03)$. In further one-way ANOVA analyses, (3) educational level $\left(F_{5,581}=\right.$ $\left.0.7, \mathrm{~ns}, \mathrm{y}^{2}=.006\right)$, (4) professional field $\left(F_{8,578}=\right.$ $\left.1.287, p>.05, \mathrm{n}^{2}=.018\right)$, (5) length of working experience $\left(F_{7,579}=0.897, \mathrm{~ns}, \mathrm{n}^{2}=.01\right)$, and $(6)$ working situation $\left(F_{3,583}=0.770, \mathrm{~ns}, \mathrm{n}^{2}=.004\right)$ had no significant effect on the level of user agency. However, there was a significant effect of (9) the categories of device chosen on user agency in one-way ANOVA $\left(F_{8,578}=8,025, p<.01, \mathrm{y}^{2}=.10\right)$.

The respondents choosing a household cleaning device indicated highest user agency
$(\mathrm{M}=2.83, \mathrm{SD}=0.83)$ and the ones choosing to focus on a personal assistant device had the lowest $(\mathrm{M}=1.99, \mathrm{SD}=0.81)$. To further investigate which differences in user agency in the different categories of devices were significant, we conducted post hoc analyses with Gabriel due to the different sizes of the samples [29]. The significant differences are indicated in the Table 2, which shows the number of people choosing a particular device category (n), the mean score on user agency (M), the standard deviations (SD), all significant differences between device categories with the significance levels indicated, and the 95\% confidence intervals.

The post hoc tests showed that respondents who chose a personal assistant device $(\mathrm{M}=1.99, \mathrm{SD}=0.81)$ were significantly lower in user agency than those who chose a smart watch/bracelet $(\mathrm{M}=2.58, \mathrm{SD}=0.79), \mathrm{p}=2,1472 \mathrm{E}-7$, with a Cohen's d effect size of -0.7328 at a $95 \%$ CI [-0.9022- -0.2676].

The personal assistant device owners also had a significantly lower user agency than those who chose a household cleaning device $(\mathrm{M}=2.83$, $\mathrm{SD}=0.83), \mathrm{p}=1,3608 \mathrm{E}-8$, with an effect size of 1.0332 at a $95 \%$ CI [-1,2678 - -,4194]. In addition, they also had a significantly lower user agency than those who chose other household device $(\mathrm{M}=2.73, \mathrm{SD}=0.74), \mathrm{p}=.000013$, with an effect size of 0.9480 at a $95 \%$ CI [-1.1911 - -0.2776].

All these differences hold at the Bonferroni-adjusted [29] alpha level of $\mathrm{p}=.00625$.

In addition, the respondents choosing a personal assistant device had a significantly lower user agency than those who chose a personal hygiene device (Mean=2.72, SD=.72), but the $\mathrm{p}=.009$ does not hold after the Bonferroni correction. The effect size was 0.9459 and the $95 \%$ CI [1,3586 - 0.0921]. Also those choosing a personal health device $(\mathrm{M}=2.59, \mathrm{SD}=0.82)$ differed from those choosing a personal assistant device ( $p=.019$, effect size $0.7335,95 \%$ CI [-1.1430-0.0484], but this does not hold after a Bonferroni correction.

Moreover, the respondents choosing a smart $\mathrm{tv} /$ videostreaming device $(\mathrm{M}=2.30, \mathrm{SD}=0.76)$ had a significantly lower user agency than those 
choosing a household cleaning device $(\mathrm{M}=2.83$, $\mathrm{SD}=0.83), \quad \mathrm{p}=.001$, with an effect size of 0.6686 and with a $95 \%$ CI [0.1302-0.9324]. This $\mathrm{p}$ is also significant at the Bonferroni-adjusted level of $\mathrm{p}=.00625$. Those who did not choose a smart device but a computer/mobile phone $(\mathrm{M}=2.34$, $\mathrm{SD}=0.61$ ) had a significantly lower user agency than those choosing a household cleaning device ( $\mathrm{p}=.011$, effect size 0.6814 , the $95 \%$ CI [0.05890.9311]), but this does not hold after Bonferronicorrection.

An independent-samples t-test was conducted to compare user agency levels between those who had (7) professional knowledge of related fields with those who did not. Results show that there was no significant difference $(t$ $(585)=-0.51, \mathrm{p}>.05)$.

An additional independent-samples t-test was also conducted to compare user agency among those who had (8) professional experience of researching, producing, marketing, or selling smart devices and those who did not. People with professional experience of smart devices $(M=2.35$, $\mathrm{SD}=0.82$ ) differed significantly from those with no such experience $(\mathrm{M}=2.50, \mathrm{SD}=0.78)(\mathrm{t}(585)=2,31$, $\mathrm{p}=.021,95 \%$ CI [0.02341-0.28769]). Thus, people with professional experience of smart devices were actually reporting lower levels of user agency than those without such experience.

\subsection{Device agency and the background variables}

The same analyses consisting of one-way ANOVAs and t-tests were conducted to investigate how the demographic and other background variables affected device agency. The overall mean of device agency in our sample was 1.31, which can be considered relatively low.

In one-way ANOVA, there was no significant effect of respondent's $(1)$ age $\left(\mathrm{F}_{4,586}=\right.$ $\left.1.61, \mathrm{p}>.05, \mathrm{p}^{2}=0.01\right)$ or $(2) \operatorname{sex}\left(\mathrm{F}_{2,584}=0.79, \mathrm{~ns}, \mathrm{n}^{2}\right.$ $=0.0027)$ on the level of device agency. Because we only had six respondents who did not identify as male or female, we also ran an independent samples t-test with only those who identified as either male or female, and obtained the same result: sex has no effect on device agency $(t(579)=-$ $0.81, \mathrm{p}>.05, \mathrm{r}=.03)$.

A one-way ANOVA did not find a significant effect of the respondents' (3) educational level $\left(\mathrm{F}_{5,581}=1.20, \mathrm{p}>.05, \mathrm{n}^{2}=0.02\right)$, (4) professional field $\left(\mathrm{F}_{8,578}=1.73, \mathrm{p}>.05, \mathrm{n}^{2}=0.02\right)$, (5) length of working experience $\left(\mathrm{F}_{7,579}=1.51, \mathrm{p}>\right.$ $\left..05, \mathrm{n}^{2}=0.018\right)$, (6) working situation $\left(\mathrm{F}_{3,583}=1.91, \mathrm{p}\right.$ $>.05, \mathrm{n}^{2}=0.01$ ), and (9) the category of chosen device $\left(\mathrm{F}_{8,578}=1.44, \mathrm{p}>.05, \mathrm{n}^{2}=0.02\right)$ on device agency.

An independent samples t-test was conducted to compare device agency among those who had (7) professional knowledge of related fields and those who did not. In this respect, people with professional knowledge did not differ significantly from people with no professional knowledge of smart devices $(t(585)=$ $-0.12, p>.05, r=0.01)$. An independent samples ttest was also conducted to compare those who had (8) professional experience of researching, producing, marketing, or selling smart devices and those who did not. People with professional experience of working with smart devices did not differ from those without such experience $(t(585)$ $=-1.34, p>.05, r=0.06)$ in terms of device agency.

\section{Implications for Human-Computer Interaction}

In this paper, we have argued that:

- agency is more than just a user's sense of control over a device,

- agency is a dimensional construct with a high pole and a low pole, and

- the agency the user attributes to themselves is a separate phenomenon from the agency attributed to the device.

In generalizing the results, it is worth noting that our population had a large portion of highly educated people with professional understanding of technology. At the same time, there is preliminary evidence in support of the theory of agency in human-smart device interaction developed in this paper. In addition, the categorization of user relationships suggested in Section 3 may be beneficial when designing an $\mathrm{HCI}$ experience. We propose that as all users 


\begin{tabular}{|c|c|c|c|c|c|c|}
\hline $\begin{array}{l}\text { Type of device } \\
\text { chosen }\end{array}$ & $\mathbf{n}$ & Mean & SD & Mean difference & & \\
\hline $\begin{array}{l}\text { 1. Household } \\
\text { cleaning devices }\end{array}$ & 53 & 2.83 & 0.83 & $\begin{array}{l}\text { personal } \\
\text { assistant } \\
\text { devices }\end{array}$ & $\begin{array}{lr}2 & \text { household } \\
\text { cleaning devices }\end{array}$ & $\begin{array}{l}\text { Confidence } \\
\text { Interval (95\%) }\end{array}$ \\
\hline $\begin{array}{l}2 . \quad \text { Other } \\
\text { household } \\
\text { devices }\end{array}$ & 41 & 2.73 & 0.74 & $0.734^{* *}$ & & $\begin{array}{l}1.1911 \\
0.2776\end{array}$ \\
\hline $\begin{array}{l}3 . \quad \text { Personal } \\
\text { hygiene devices }\end{array}$ & 15 & 2.72 & 0.72 & $0.725^{*}$ & & $\begin{array}{l}1.3586 \\
-0.0921\end{array}$ \\
\hline $\begin{array}{l}\text { 4. Personal } \\
\text { health devices }\end{array}$ & 23 & 2.59 & 0.81 & $0.596^{*}$ & & $\begin{array}{lll}1.1430 & - \\
0.0484 & & -\end{array}$ \\
\hline $\begin{array}{lr}5 . & \text { Smart } \\
\text { watches/bracelets }\end{array}$ & 175 & 2.58 & 0.79 & $0.585^{* *}$ & & $\begin{array}{l}0.9022 \\
0.2676\end{array}$ \\
\hline $\begin{array}{l}\text { 6. Computers } \\
\text { and smartphones }\end{array}$ & 76 & 2.34 & 0.61 & & $-0.495^{*}$ & $\begin{array}{ll}-0.0589 & - \\
0.9311 & \end{array}$ \\
\hline $\begin{array}{l}\text { 7. Smart TVs and } \\
\text { videostreaming } \\
\text { devices }\end{array}$ & 112 & 2.30 & 0.76 & & $-0.531^{* *}$ & $\begin{array}{l}-0.1302- \\
0.9324\end{array}$ \\
\hline $\begin{array}{l}8 . \quad \text { Personal } \\
\text { assistant devices }\end{array}$ & 86 & 1.99 & 0.81 & & $0.844^{* *}$ & $\begin{array}{l}1.2678 \\
0.4194\end{array}$ \\
\hline
\end{tabular}

attribute some degree of agency to themselves and to their device, all users can be profiled as Controller, Collaborator, Detached, or Victim (see figure 1).

Evidence presented in Sections 4.3 and 4.4 suggests that these profiles are not dependent of background variables such as gender, age, or education. However, they are dependent of the device. Consequently, we theorize that a user could be characterized by a collection of profiles, one for each device that he/she owns.

At the same time, agency is not a static concept. The relationship profiling is dynamic and thus, a potential way to illustrate the user's journey with their device. We suggest that the user can have a positive relationship with their device both when they attribute high and low agency to their device. We further hypothesize that in all cases, the user should perceive themselves as agentic in the interaction.

We propose that smart device interfaces should be fine-tuned with the particular user profile in order to foster the Detached and Victim users' evolution towards Controller and/or Collaborator. In particular, we recommend the following points for increasing the agency for users who are inclined to develop Detached or Victim dynamics:

- do not create too high demands/expectations for the user in terms of what they should be able to do with the device

- downplay the variety of functions the device has in order not to invite the user to see the device as controlling him

- give the user very clear instructions on what he can do with the device

- underline how the features of the device are relevant in terms of the user's needs and goals

- provide continuous positive feedback on what the users have been able to do with the device

In other words, for Detached or Victim dynamics, simplicity is to be preferred over expressiveness. In addition, what the device can 
do for the user's practical goals is more important than sophisticated features.

We hypothesize that as the user's agency increases, more complex device features may be introduced to further foster a more collaborative relationship with the device.

In our results, personal assistant devices stood out as a group of their own, as the respondents choosing to focus on them felt less agentic than the users of other devices (see Table 2). These sophisticated devices are designed to invite people perceive them as more than just devices, with human-like (anthropomorphized) features. This creates high expectations for what the user should be able to do with them. Thus, these devices create for the user frustrating experiences of feeling that they are not able to use the gadget optimally. Therefore, the interfaces should be fine-tuned to increase the user's feeling that they are flexibly able to use the device to do things that are relevant for them in a particular situation. For example, the user's goals and the device's features should be very clearly aligned to prevent user overwhelm. A feedback system should be implemented, giving the user positive reinforcement on how they have been using the gadget in relation to their specific goals and needs. In all cases, the basis of the interaction should be what the user wants to do and achieve with the device, and a feedback system adjusted for the user's level of agency should accompany it.

People with professional experience of smart devices had lower user agency. It is plausible that, due to their more in-depth knowledge of devices in general, this group has higher expectations of themselves in terms of what they can do with the device. Interface designers should dedicate particular attention to enhancing the user agency of these kind of techaware people.

In conclusion, an interface should be designed for maximizing the user agency in the interaction. Moreover, accumulating interactions with the device should be designed to increase user agency over time.

\section{Conclusions}

In this paper, we provide empirical evidence that people simultaneously attribute agency to their smart devices and to themselves. This attribution of agency also defines, in the Gibsonian sense, how the user is leveraging the affordances of the smart device. Consequently, the bi-directional attribution of user and device agency can be used as a measure for understanding if the user masters the device's potentials to the fullest or not.

In this work, we have demonstrated how user agency and device agency can be used as proxies for understanding how a user is experiencing his relationship with the device. However, further research is needed in order to study if these constructs also function as mediators for other factors of human-device interaction. In this respect, the theory of agency in human-smart device interaction could be part of a bigger model.

"Things we own might end up owning us $^{\prime \prime 1}$ in case we are unaware of the agency we attribute to ourselves and our devices. Perhaps the secret of a balanced relationship with our gadgets is in making an aware decision of when and how to be "owned" by the device and when not.

\section{References}

[1] H. Limerick, D. Coyle, and J. W. Moore, “The Experience of agency in human-computer interactions: a review", Frontiers in Human Neuroscience, pp. 1-10, 2014. doi: 10.3389/fnhum.2014.00643

[2] B. Shneiderman, "Direct manipulation for comprehensible, predictable and controllable user interfaces", in IUI '97: Proceedings of the 2nd international conference on Intelligent user interfaces, Orlando, FL, USA, January, 1997, J. Moore, E. Edmonds, A. Puerta, Eds. New York: Association for Computing Machinery, 1997. pp. 33-39.

1 Original: "The things you own end up owning you", Tyler Durden in Fight Club (1999). 
[3] J.J. Gibson, "The Theory of Affordances", In Perceiving, Acting, and Knowing. Toward an Ecological Psychology, R.E. Shaw and J. Bransford, Eds. Hillsdale, N.J: Lawrence Erlbaum Associates, 1977, pp. 67-82.

[4] H. Toivonen, "Constructions of agency and nonagency in psychotherapy: The 10 Discursive Tools Model" Ph.D. dissertation, Dept. Psych., University of Jyväskylä., Jyväskylä, $\quad$ Finland, 2019. https://jyx.jyu.fi/handle/123456789/65808

[5] J.E. McEneaney, "Agency Attribution in HumanComputer Interaction", In Engineering Psychology and Cognitive Ergonomics EPCE 2009, Lecture Notes in Computer Science, vol 5639, D. Harris, Ed. Berlin: Springer, 2009. pp. 81-90. doi:10.1007/978-3-642-027284_9(2009).

[6] J.E. McEneaney, "Agency Effects in HumanComputer Interaction", International Journal of HumanComputer Interaction, vol. 29, no. 12, pp. 798-813, 2009. doi: 10.1080/10447318.2013.777826(2013)

[7] A. Gillespie, "Position exchange: The social development of agency", New Ideas in Psychology, vol. 30, pp. 32-46, 2012. doi:10.1016/j.newideapsych.2010.03.004

[8] H.-H. Kögler, "Agency and the other: On the intersubjective roots of self-identity", New Ideas in Psychology, vol. 30, pp. 47-64, 2012.

[9] J. McCarthy and P. Wright, "Putting 'felt-life' at the centre of human-computer interaction (HCI)", Cognition Technology and Work, vol. 7, no. 4, pp. 262-271, 2005. doi:10.1007/s10111-005-0011-y

[10] A. Sato and A. Yasuda, "Illusion of sense of selfagency: Discrepancy between the predicted and actual sensory consequences of actions modulates the sense of self-agency, but not the sense of self-ownership" Cognition, vol. 94, no. 3, pp. 241-255, 2005. doi:10.1016/j.cognition.2004.04.003

[11] D. A. Norman, The psychology of everyday things. New York: Basic Books, 1988.

[12] I. Hutchby, "Technologies, Texts, and Affordances", Sociology, vol. 35, no. 2, pp. 441-456, 2001. doi:10.1177/S0038038501000219
[13] G. Pozzi, F. Pigni, and C. Vitari, "Affordance Theory in the IS Discipline: A Review and Synthesis of the Literature", in 20 th American Conference on Information Systems AMCIS 2014 Proceedings, Savannah, GA, United States, vol. 13, pp. 1-12, 2014.

[14] B. Berberian, "Man-Machine teaming: A problem of agency", IFAC-PapersOnLine, vol. 51, no. 34, 118-123, 2019. doi:10.1016/j.ifacol.2019.01.049(

[15] M-L. Boudreau and D. Robey, “Enacting Integrated Information Technology: A Human Agency Perspective“, Organization Science, vol. 16 no. 1, pp. 318, 2005. doi:10.1287/orsc. 1040.0103

[16] D. G. Johnson and M. Verdicchio, "AI, agency and responsibility: the VW fraud case and beyond", AI $\mathcal{E}$ Society, vol. 34, pp. 639-647. doi:10.1007/s00146-0170781-9(2019).

[17] T.P. Novak and D.L. Hoffman, "Relationship journeys in the internet of things: a new framework for understanding interactions between consumers and smart objects", Journal of the Academy of Marketing Science, vol. 47, pp. 216-237, 2019. doi:10.1007/s11747018-0608-3

[18] F. Schweitzer, R. Belk, W. Jordan, and M. Ortner, "Servant, friend or master? The relationships users build with voice-controlled smart devices", Journal of Marketing Management, vol. 35, no. 7-8, pp. 693-715, 2019. doi:0.1080/0267257X.2019.1596970

[19] B. Shneiderman, C. Plaisant, M. Cohen, S. Jacobs, and N. Elmqvist, Designing the User Interface: Strategies for Effective Human-Computer Interaction: Sixth Edition. Boston: Pearson, 2016.

[20] A. Dillon, "Beyond usability: process, outcome and affect in human-computer interactions", Canadian Journal of Library and Information Science vol. 26, no. 4, pp. 57-69, 2002.

[21] M. Hassenzahl, "The Interplay of Beauty, Goodness, and Usability in Interactive Products" Human-Computer Interaction vol. 19, pp. 319-349, 2004.

[22] D-H. Shin, "Cross-analysis of usability and aesthetic in smart devices: what influences users' preferences?" Cross Cultural Management, vol. 19, no. 4, pp. 563-587, 2012. doi: 10.1108/13527601211270020 
[23] H.-W. Kim, S. Gupta, \& J. Koh, "Investigating the intention to purchase digital items in social networking communities: A customer value perspective", Information $\mathcal{E}$ Management, vol. 48, no. 6, pp. 228-234. doi:10.1016/j.im.2011.05.0042011

[24] R.W. Belk, "Possessions and the Extended Self", Journal of Consumer Research, vol. 15, no. 2, pp. 139-168, 1988.

[25] A. Waytz, J. Heafner, and N. Epley, "The mind in the machine: Anthropomorphism increases trust in an autonomous vehicle", Journal of Experimental Social Psychology vol. 52, pp. 113-117, 2014. doi:10.1016/j.jesp.2014
[26] P. Kline, An easy guide to factor analysis. London: Routledge, 2002.

[27] J. Wim, W. Katrien, D. P. Patrick, and V. K. Patrick, Marketing Research with SPSS. Prentice Hall; Pearson Education, 2008.

[28] M. J Blanca, J. Arnau, R. Bono, and R. Bendayan, "Non-normal data: Is ANOVA still a valid option?" Psicothema vol. 29, no. 4, pp. 552-557, 2017. doi: 10.7334/psicothema2016.383

[29] A. Field, Discovering statistics using SPSS (2nd ed.), London: Sage Publications, 2005. 